\title{
Forecasting the Number of Offset Printing Machine Breakdowns Using the Support Vector Machine (SVM) Metdhod
}

\section{Peramalan Jumlah Breakdown Mesin Printing Offset Menggunakan Metode Support Vector Machine (SVM)}

\author{
Nafis Khumaidah $^{1}$, Tedjo Sukmono ${ }^{2}$ \\ \{nafis.maidah@gmail.com ${ }^{1}$, thedjoss@umsida.ac.id $\left.{ }^{2}\right\}$ \\ ${ }^{1}$ Program Studi Teknik Industri, Fakultas Sains dan Teknologi, \\ Universitas Muhammadiyah Sidoarjo
}

\begin{abstract}
PT. MJT is a company engaged in manufacturing that produces various types of plastic tubes for cosmetic packaging. Production activities at PT. MJT uses an intermittent process, which in the printing division requires a longer total setup time because this process produces various types of specifications of goods to order. This has an effect on the amount of engine breakdown. The purpose of this research is to try the method of forecasting the number of breakdowns for offset printing machines at PT. MJT. One of the methods used in this research is the Support Vector Machine method. Support Vector Machine is a method that can help predict the number of breakdowns that will be experienced by the offset printing machine at PT. MJT. Support vector machine is a method that can reduce the error value in forecasting compared to other methods. From this research, it is hoped that it can produce a forecast of the number of breakdowns for offset printing machines at PT. MJT for a period of one year or twelve periods.
\end{abstract}

Keywords : Forecasting, damage, break down, Support Vector Machine (SVM).

Abstrak-PT. MJT merupakan perusahaan yang bergerak dibidang manufaktur yang memproduksi berbagai jenis tube plastik untuk kemasan kosmetik. Kegiatan produksi pada PT. MJT menggunakan sistem produksi terputus (intermittent process) yang mana pada devisi printing memerlukan total waktu setup yang lebih lama karena proses ini memproduksi berbagai jenis spesifikasi barang sesuai pesanan. Hal ini berpengaruh terhadap besarnya breakdown mesin. Tujuan dari penelitian ini yaitu mencoba metode peramalan jumlah breakdown mesin printing offset pada PT. MJT. Salah satu metode yang digunakan dalam penelitian ini adalah metode Support Vector Machine. Support Vector Machine merupakan metode yang dapat membantu untuk memprediksi jumlah breakdown yang akan dialami oleh mesin printing offset pada PT. MJT. Support vector machine dapat dikatakan metode yang dapat memperkecil nilai kesalahan pada peramalan dibandingkan metode-metode yang lain. Dari Penelitian ini diharapkan agar dapat menghasilkan peramalan jumlah breakdown mesin printing offset pada PT. MJT dalam jangka waktu satu tahun atau dua belas periode.

Kata kunci : Peramalan, kerusakan, break down, Support Vector Machine (SVM).

\section{PENDAHULUAN}

Sebagai salah satu perusahaan besar yang memproduksi kemasan dalam bentuk tube, single dan multi layer dari bahan biji plastik polyethylene (PE), untuk produk kosmetik, farmasi, Amenties dan kemasan lainnya. PT, MJT ini telah menerapkan standart ISO 9001: 2015, terkecuali pada desain, karena menyebutkan spesifikasi dari pelanggan secara lengkap sampai tingkat yang paling detail dan hanya membuat produk persis seperti yang ditentukan pelanggan. PT. MJT ini telah memiliki standar-standar dalam proses kerja atau produksinya. Dan perusahaan ini sangat menekan karyawan dalam menjalankan pekerjaannya sesuai dengan standart operasional prosedur (SOP).

PT. MJT ini memiliki kegiatan produksi dengan sistem produksi terputus (intermittent process) yang mana pada devisi printing ini memerlukan total waktu setup yang lebih lama karena proses ini memproduksi berbagai jenis spesifikasi barang sesuai pesanan, sehingga adanya pergantian jenis barang yang diproduksi akan membutuhkan kegiatan setup yang berbeda. Dengan adanya setup mesin yang tinggi, sehingga berdampak pada tingginya tingkat breakdown mesin. Hal tersebut terjadi salah satunya diakibatkan karena kerusakan mesin yang berkaitan dengan maintenance. Jika terjadi kerusakan pada mesin dan preventive maintenance tidak dilakukan dengan baik dan sesegera mungkin maka akan menganggu kelancaran dalam kegiatan produksi maupun dapat mempengaruhi kualitaas produk yang dihasilkan sehingga dapat merugikan perusahaan..

Meninjau dari sasaran mutu perusahaan yang salah satunya merupakan upaya menekan tingkat breakdown time tahun 2019 sebesar 19,14\% menjadi 10\% ditahun 2020 ini, oleh karena itu akan dilakukan penelitian ini yang bertujuan untuk mengetahui prediksi kerusakan-kerusakan apa saja yang akan terjadi pada 
Procedia of Engineering and Life Science Vol. 1. No. 2 Juni 2021

Seminar Nasional \& Call Paper Fakultas Sains dan Teknologi (SENASAINS $2^{\text {nd }}$ )

Universitas Muhammadiyah Sidoarjo

mesin offset pada devisi printing dengan menggunakan metode Support Vector Machine (SVM). Metode ini digunakan untuk memprediksi kerusakan pada mesin dan bagaimana pengujian untuk menghasilkan nilai akurasi klasifikasi data menggunakan algoritma support vector machine (SVM). Yang diharapkan dapat membantu menyelesaikan permasalahan break down mesin yang tinggi pada PT. MJT.

\section{METODE}

Data yang digunakan adalah data harian dari aktivitas break down 9 mesin printing offset pada tahun 2015-2019. Data tersebut diperoleh dari data arsip break down mesin yang dimiliki oleh PT. MJT pada priode tahun 2015-2019. penelitian ini yang bertujuan untuk mengetahui prediksi kerusakan-kerusakan apa saja yang akan terjadi pada mesin offset pada devisi printing dengan menggunakan metode Support Vector Machine (SVM). Metode ini digunakan untuk memprediksi kerusakan pada mesin dan bagaimana pengujian untuk menghasilkan nilai akurasi klasifikasi data menggunakan algoritma Support Vector Machine (SVM). Yang diharapkan dapat membantu menyelesaikan permasalahan break down [1]mesin yang tinggi pada PT. MJT.

Adapun tahapan pengolahan dan pengujian data yang akan dilakukan yaitu :

1. Klasterisasi data

2. Normalisasi data

3. Pembagian data Training dan Testing

4. Pembuatan model SVM

5. Peramalan data

6. Evaluasi hasil peramalan

\section{HASIL DAN PEMBAHASAN}

Pada bagian ini akan membahas mengenai pengolahan data yang diperoleh dari aktivitas break down 9 mesin printing offset pada tahun 2015-2019. Pengolahan data yang pertama akan mengolah data kerusakan mesin yang bertujuan untuk mendapatkan model peramalan yang sesuai dengan menggunakan metode support vector machine (SVM).

\section{A. Klasterisasi Data}

Pada 20 kerusakan pada mesin printing offset dibagi menjadi 3 klaster yaitu tinggi, sedang dan rendah berdasarkan jumlah kerusakan aktual[2]. Kemudian masing-masing klaster dipilih 2 kerusakan setiap klasternya[3]. Setiap kerusakan yang dipilih akan diramalkan sehingga total ada 6 kerusakan mesin.

Tabel 1. Hasil Klasterisasi Beserta Total Kerusakan Mesin

\begin{tabular}{clccc}
\hline No. & \multicolumn{1}{c}{ Observation } & Class & Distance to centroid & Total \\
\hline 1 & Pangkon Corona & 3 & 11 & 1134 \\
\hline 2 & Gear Roll Varnish & 3 & 11 & 1156 \\
\hline 3 & Corona Box & 1 & 78,4 & 1433 \\
\hline 4 & Mekanik Sleeve & 1 & 76,4 & 1435 \\
\hline 5 & Mandrel @ 16-22 & 1 & 73,4 & 1438 \\
\hline 6 & Encoder & 1 & 46,4 & 1465 \\
\hline 7 & Gearbox & 1 & 29,4 & 1482 \\
\hline 8 & Roll Varnish & 1 & 24,4 & 1487 \\
\hline 9 & Uv Lamp 1,2,3 & 1 & 19,6 & 1531 \\
\hline 10 & Join Take Off & 1 & 32,6 & 1544 \\
\hline 11 & Gear Helikel & 1 & 45,6 & 1557 \\
\hline 12 & Loading Pendorong & 1 & 230,6 & 1742 \\
\hline 13 & Fan Belt Loader & 2 & 251,25 & 1802 \\
\hline 14 & As Cam Perata & 2 & 101,25 & 1952 \\
\hline 15 & Od 100 (Ruber Axle) & 2 & 95,25 & 1958 \\
\hline 16 & Kampas Kopling Station & 2 & 17,75 & 2071 \\
& & & &
\end{tabular}


Procedia of Engineering and Life Science Vol. 1. No. 2 Juni 2021

Seminar Nasional \& Call Paper Fakultas Sains dan Teknologi (SENASAINS 2nd)

Universitas Muhammadiyah Sidoarjo

\begin{tabular}{clccc}
\hline & Ink & & & \\
\hline 17 & Motor Penggerak Roll & 2 & 26,75 & 2080 \\
\hline 18 & Roll Ink & 2 & 120,75 & 2174 \\
\hline 19 & Rante Axle & 2 & 131,75 & 2185 \\
\hline 20 & Cam Perata & 2 & 150,75 & 2204 \\
\hline
\end{tabular}

Dari hasil klasterisasi tersebut dipilih 6 jenis kerusakan dengan mengambil masing-masing 2 jenis kerusakan pada setiap kelas. Pemilihan tersebut berdasarkan total kerusakan terendah dan tertinggi pada setiap kelas[4].

\section{B. Uji Normalitas}

Uji Normalitas dilakukan menggunakan aplikasi Minitab dengan tujuan untuk menilai sebaran data kerusakan mesin printing offset tersebut berdistribusi normal atau tidak. Data dinyatakan normal jika nilai $P$-Value (Signifikansi) lebih besar dari 5\% atau 0,05 [5].

Tabel 2. Tabel Hasil Uji Normalitas

\begin{tabular}{lccc}
\hline \multicolumn{1}{c}{ Jenis Kerusakan } & $P$-Value & Hasil & Keterangan \\
\hline Pangkon Corona & 0,05 & 0,05 & Normal \\
\hline Gear Roll Varnish & 0,139 & $>0,050$ & Normal \\
\hline Corona Box & 0,088 & $>0,050$ & Normal \\
\hline Loading Pendorong & 0,141 & $>0,050$ & Normal \\
\hline Fan Belt Loader & 0,15 & $>0,050$ & Normal \\
\hline Cam Perata & 0,15 & $>0,050$ & Normal \\
\hline
\end{tabular}

\section{Pembagian Data}

Pembagian data dilakukan untuk membagi menjadi 2 bagian data yaitu untuk data pelatihan (Training) dan data pengujian (Testing). Pembagian data ini dibagi menjadi presentase 70:30 dari 6 produk yang dipilih[6]. Pada data pelatihan akan digunakan dalam menentukan model SVM yang nantinya digunakan untuk peramalan. Model SVM akan dipilih yang terbaik sebelum diaplikasikan pada data pengujian

Tabel 3. Pembagian Data Pelatihan dan Pengujian.

\begin{tabular}{lccc}
\hline Jenis Kerusakan & Total Data & Data Training & Data Testing \\
\hline Cam Perata & 60 & 36 & 24 \\
\hline Corona Box & 60 & 36 & 24 \\
\hline Fan Belt Loader & 60 & 36 & 24 \\
\hline Gear Roll Varnish & 60 & 36 & 24 \\
\hline Loading Pendorong & 60 & 36 & 24 \\
\hline Pangkon Corona & 60 & 36 & 24 \\
\hline
\end{tabular}

\section{Pembuatan Model SVM}

Pembuatan model hingga peramalan pada penelitian ini digunakan software Rstudio untuk membantu mengolah data. Sebelum masuk pada peramalan dilakukan pelatihan data terlebih dahulu untuk mengetahui modelnya dan parameter yang mengikuti model tersebut[7].

Tabel 4. Hasil Model dan Parameter Tiap Jenis Kerusakan

\begin{tabular}{|c|c|c|c|c|}
\hline \multirow{2}{*}{ Jenis Kerusakan } & \multirow{2}{*}{ Tipe Karnel } & \multicolumn{3}{|c|}{ Parameter } \\
\hline & & Epsilon (₹) & $C(\mathrm{c})$ & $\operatorname{Gamma}\left({ }^{\gamma}\right)$ \\
\hline Cam Perata & Radial Basis Function & 0,4 & 0,03125 & 0,01563 \\
\hline Corona Box & Radial Basis Function & 0,1 & 0,03125 & 0,01563 \\
\hline
\end{tabular}


Procedia of Engineering and Life Science Vol. 1. No. 2 Juni 2021

Seminar Nasional \& Call Paper Fakultas Sains dan Teknologi (SENASAINS 2nd)

Universitas Muhammadiyah Sidoarjo

\begin{tabular}{llccc}
\hline Fan Belt Loader & Radial Basis Function & 0,3 & 0,0625 & 8 \\
\hline Gear Roll Varnish & Radial Basis Function & 0,2 & 2 & 0,01563 \\
\hline Loading Pendorong & Radial Basis Function & 1 & 8 & 4 \\
\hline Pangkon Corona & Radial Basis Function & 0,7 & 64 & 0,5 \\
\hline
\end{tabular}


Procedia of Engineering and Life Science Vol. 1. No. 2 Juni 2021

Seminar Nasional \& Call Paper Fakultas Sains dan Teknologi (SENASAINS $2^{\text {nd }}$ )

Universitas Muhammadiyah Sidoarjo

Pada hasil parameter ini telah diuji menggunakan grid search optimization dan hasil yang terbaiklah yang diambil dengan error terkecil[8].

\section{E. Peramalan Data}

Setelah didapatkan hasil modelnya[9] yakni tipe kernel maupun parameternya maka selanjutnya dilakukan peramalan pada data Training dan data Testing. Peramalan pada data Training dan data Testing ini akan berlanjut ke peramalan pada 12 periode selanjutnya.

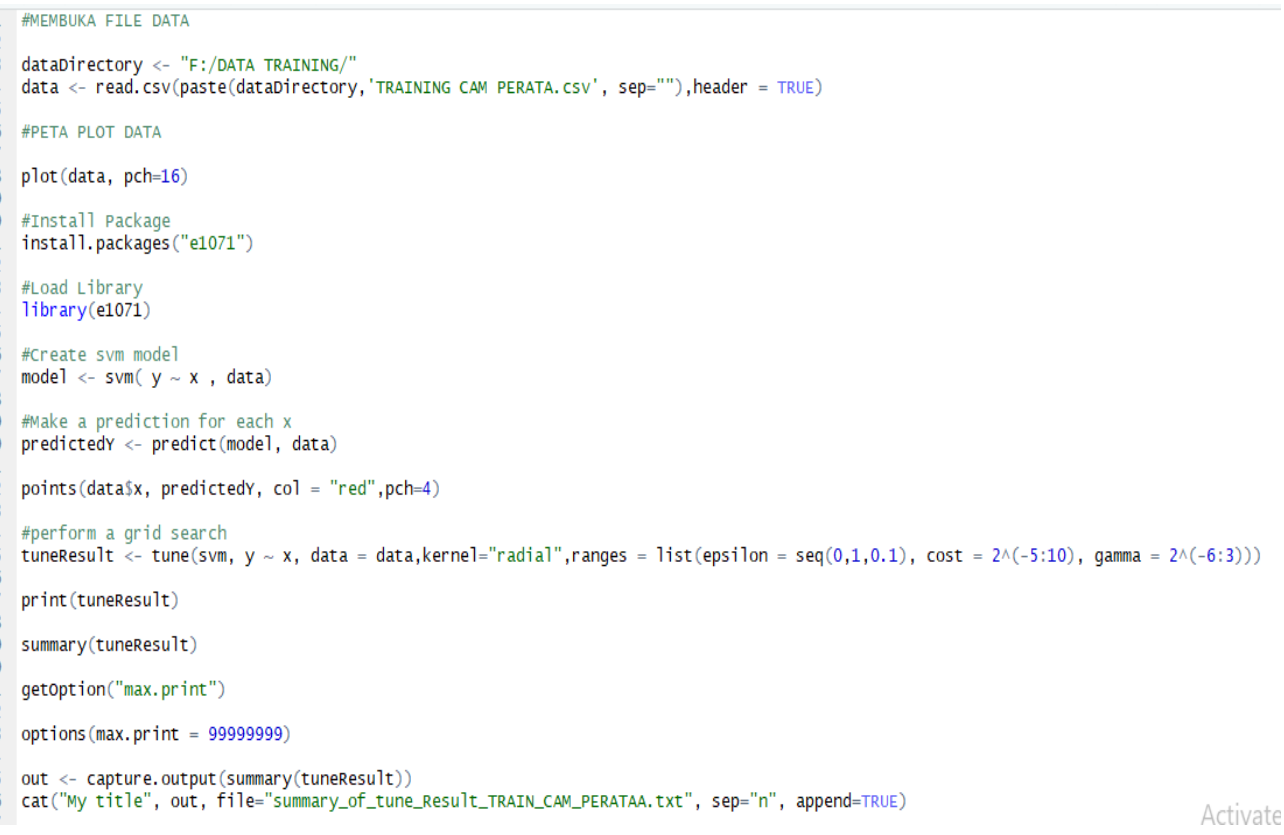

Gambar 1. Source Code Cam Perata (data training)

Peramalan dilakukan menggunakan aplikasi RStudio dengan mengolah data Training dan Testing sehingga menghasilkan data Forecasting.

Tabel 5. Hasil Peramalan Cam Perata 12 Periode Kedepan

\begin{tabular}{cc} 
Periode & Forecasting \\
\hline Jan-20 & 40 \\
\hline Feb-20 & 42 \\
\hline Mar-20 & 42 \\
\hline Apr-20 & 42 \\
\hline May-20 & 42 \\
\hline Jun-20 & 42 \\
\hline Jul-20 & 42 \\
\hline Aug-20 & 42 \\
\hline Sep-20 & 42 \\
\hline Oct -20 & 42 \\
\hline Nov-20 & 42 \\
\hline Dec-20 & 42 \\
\hline
\end{tabular}




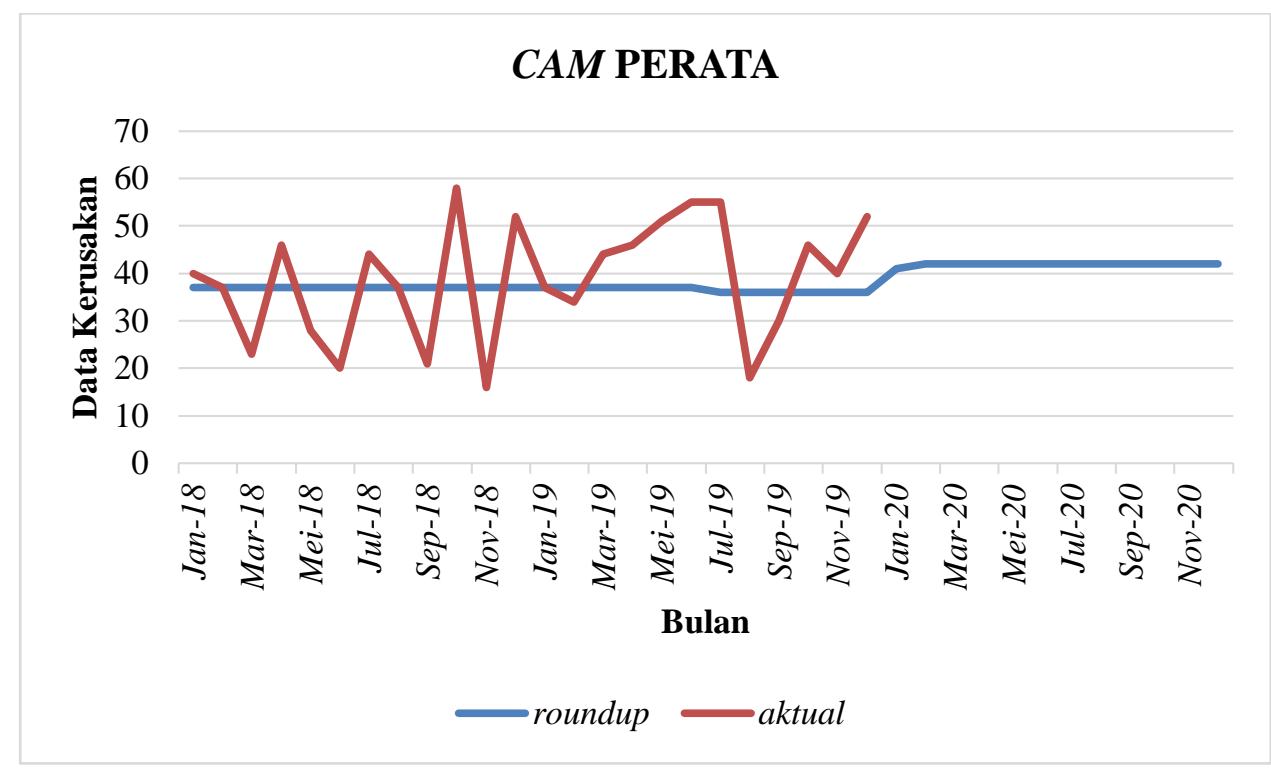

Gambar 2. Grafik Hasil Peramalan Cam Perata

Dari gambar diatas dapat menunjukkan bahwa pola peramalan pada kerusakan Cam Perata tersebut berpola horizontal pada saat data masih berada di data testing. Namun ketika masuk pada peramalan 12 periode kedepan hasil peramalan menunjukkan pola naik pada periode kedua dan sampai pada periode keduabelas data berpola horizontal atau stagnan.

\section{F. Evaluasi Hasil Peramalan}

Setelah didapatkan hasil peramalan dari proses sebelumnya maka akan dihitung dan dicari Mean Square Error (MSE) dan Mean Percentage Absolute Percentage Error (MAPE) [10]. Perhitungan untuk mencari MSE dan MAPE mengikuti rumus. Berikut perhitungan dari MSE dan MAPE dari Cam Perata.

$$
M S E=\sum_{t=1}^{n} \frac{\left(X_{t}-F_{t}\right)^{2}}{n} \quad M A P E=\left(\frac{100 \%}{n}\right) \sum_{t=1}^{n} \frac{\left|X_{t}-F_{t}\right|}{X_{t}}
$$

Di mana:

$\mathrm{Xt}=$ Data actual pada periode $\mathrm{t}$

$\mathrm{Ft}=$ Nilai peramalan pada periode $\mathrm{t}$

$\mathrm{n}=$ Jumlah data

Kemampuan peramalan sangat baik jika memiliki nilai MAPE kurang dari 10\% dan mempunyai kemampuan peramalan yang baik jika nilai MAPE kurang dari $20 \%$.

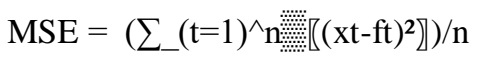

$$
\begin{aligned}
& \text { MSE }=\left((37-40)^{2}+(37-41)^{2}+\cdots+(36-33)^{2}\right) / 36 \\
& \text { MSE }=(9+16+\cdots+9) / 36 \\
& \mathrm{MSE}=148
\end{aligned}
$$

Berikut perhitungan MAPE:

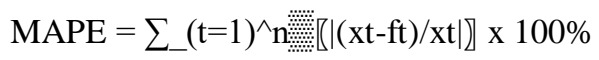

MAPE $=|((37-40)) / 37+((37-41)) / 37+\cdots+((36-33)) / 36| \times 100 \%$ 
Procedia of Engineering and Life Science Vol. 1. No. 2 Juni 2021

Seminar Nasional \& Call Paper Fakultas Sains dan Teknologi (SENASAINS $2^{\text {nd }}$ )

Universitas Muhammadiyah Sidoarjo

MAPE $=28,85 \times 100 \%$

MAPE $=2885 \%$

Dari perhitungan MSE dan MAPE diatas dilakukan pada keseluruhan data Training dan data Testing dari tiap produk. Berikut hasil dari perhitungan MSE dan MAPE.

Tabel 6. Hasil Perhitungan MSE dan MAPE

\begin{tabular}{lcccc}
\hline \multirow{2}{*}{ Produk } & MAPE Training & MAPE Testing & MSE Training & MSE Testing \\
\hline Cam Perata & $2885 \%$ & $2906 \%$ & 148 & 160 \\
\hline Corona Box & $2850 \%$ & $2847 \%$ & 63 & 57 \\
\hline Fan Belt Loader & $1834 \%$ & $2220 \%$ & 41 & 57 \\
\hline Gear Roll Varnish & $2170 \%$ & $2580 \%$ & 29 & 34 \\
\hline Loading Pendorong & $2070 \%$ & $2201 \%$ & 47 & 64 \\
\hline Pangkon Corona & $2408 \%$ & $2864 \%$ & 25 & 40 \\
\hline
\end{tabular}

MSE merupakan Metode yang menghasilkan kesalahan-kesalahan sedang yang kemungkinan lebih baik untuk kesalahan kecil, tetapi kadang menghasilkan perbedaan yang besar. MSE merupakan cara kedua untuk mengukur kesalahan peramalan keseluruhan. MAPE merupakan "Mean Absolute Percentage Error (MAPE) dihitung dengan menggunakan kesalahan absolut pada tiap periode dibagi dengan nilai observasi yang nyata untuk periode itu. Kemudian, merata-rata kesalahan persentase absolut tersebut. MAPE merupakan pengukuran kesalahan yang menghitung ukuran presentase penyimpangan antara data aktual dengan data peramalan [10].

\section{KESIMPULAN}

Peramalan jumlah breakdown mesin printing offset menggunakan metode SVM didapatkan peramalan jumlah breakdown mesin printing offset 12 periode kedepan pada 6 jenis kerusakan. Cam Perata memiliki peramalan jumlah breakdown mesin berurutan dari periode Januari hingga Desember sebanyak 40, 42, 42, 42, 42, 42, 42, 42, 42, 42, 42, 42. Dengan demikian penelitian ini akan membantu dalam peramalan pengadaan jumlah sparepart dan penyediaan tenaga perbaikan mesin agar mesin segera mendapatkan perbaikan dan proses produksi tetap berjalan dengan baik.

\section{REFERENSI}

[1] Assauri, S. 2016. Manajemen Operasi Produksi. Jakarta: PT. Raja Grafido Persada.

[2] Jibril, dkk. (2017). Neurodevelopment of HIV-Exposed and HIV-Unexposed Uninfected Childern at 24 Mount. Am Acad Pediatrics.

[3]Sibuea, F. L., \& Sapta, A. (2017). Pemetaan Siswa Berprestasi Menggunakan Metode K-Means Clustering. JURTEKSI (Jurnal Teknologi dan Sistem Informasi), 4(1).

[4] Gustientiedina., Adiya, M. H., \& Desnelita, Y. (2019). Penerapan Algoritma K-Means Untuk Clustering Data Obat-Obatan Pada RSUD Pekanbaru. Jurnal Nasional Teknologi dan Sistem Informasi, 5(1).

[5] Sugiyono, (2017). Metode Penelitian Kuantitatif, Kualitati dan R\&D. Bandung.

[6] Krisandi, dkk. (2013). Algoritma K-Nearest Neighbor dalam Klasifikasi Data Hasil Produksi Kelapa Sawit pada PT. Minamas Kecamatan Paridu. Bulletin Ilmiah Math. Stat. dan Terapannya (Bimaster).

[7] Drajana, I. C. R. 2017. Metode Support Vector Machine dan Forward Selection Prediksi Pembayaran Pembelian Bahan Baku Kopra. ILKOM Jurnal Ilmiah, 9(2), 116-123.

[8] Septiningrum, L., Yasin, H., Sugito. (2015). Prediksi Indeks Harga Saham Gabungan Menggunakan Support Vector Regression (SVR) dengan Algoritma Grid Search. Jurnal Gaussian, 4(2).

[9] Permana, R. A., \& Sahara, S. 2019. Metode Support Vector Machine Sebagai Penentu Kelulusan Mahasiswa pada Pembelajaran Elektronik. Jurnal Khatulistiwa Informatika, 7(1), 50-58.

[10] Margo, K., \& Pendawa, S. (2015). Analisa dan Penerapan Metode Single Exponential Smoothing untuk Prediksi Penjualan pada Periode Tertentu. Prosiding SNATIF. 